\title{
Abusive Supervision and Work-Family Conflict: A Mediation Model of Organizational Justice and Psychological Distress
}

\author{
Lei $\mathrm{Ju}^{1}$, Xiu-li Jing ${ }^{2, *}$ and Zhong Lin $^{3}$ \\ ${ }^{1}$ Dongbei University of Finance and Economics, China \\ ${ }^{2}$ Shenzhen Tourism College of Jinan University, Overseas Chinese Town, Nanshan District, Shenzhen, Guangdong Province, \\ China 518053 \\ ${ }^{3}$ Dongbei University of Finance and Economics, China \\ juleidufe@163.com,jing_xl@sz.jnu.edu.cn, linzhongdufe@126.com
}

\begin{abstract}
In the special culture context of China, abusive supervision is common in enterprise. This leads to injustice and psychological distress of employees. Based on "Kicked the dog effect", this stress from work can transfer to family. Work-family conflict not only affects social stability because of high divorce rate, but also causes negative behavior consequences in organization, even affects organizational performance and strategic formulation. Clearing up the functional mechanism of abusive supervision and work-family conflict is the only way to solve this problem. Based on the analysis of literature, this thesis studies the functional mechanism model between abusive supervision and work-family conflict from the perspective of the mediator of organizational justice and psychological distress.
\end{abstract}

Index Terms - Abusive supervision, Work-family Conflict, Organizational justice, Psychological distress.

\section{Introduction}

Work-family conflict is one of the main stresses of nowadays Chinese labor. It can cause family abuse, even devoice, then affect social stability, and contradict the construction of harmonious society. It also can lead to job dissatisfaction, turnover, work stress and other negative consequences of employees [1-2], and affects organizational performance, psychological contract, organizational commitment [3-5], even organizational strategic formulation [6-7].

In theory, work-family conflict (WFC) is an important research topic in organizational behavior and human resource management areas. This topic is a huge challenge to individual and organization [8]. The researches on WFC maintain steady growth for thirty years [9]. The researches on the effect of abusive supervision on WFC are already receives more and more attention in academia [9-11]. However, the research on abusive supervision is still in early stage, and its relation with WFC is an even newer research subject. The factional mechanism between abusive supervision and WFC is still clear; the mediation mechanism is still under debate.

\section{Concept Definition}

A. Abusive Supervision

The concept of abusive supervision proposed by Tepper (2000) [12]. The concept of abusive supervision is still under discussion. Mitchell and Ambrose (2007) [13] define abusive supervision as one kind of aggressive behavior in work place. However, Tepper (2007) [6] disagree with this definition. The conception of abusive supervision proposed by Tepper (2000) [12] has already gain acceptance by most researchers and used most widely. So this thesis follows his definition, define abusive supervision as the subordinates' perception of verbal or nonverbal hostile acts which the supervisor continuously performances, not including the aggression of physical contact [12]. Actually, in the perspective of concept, abusive supervision is the description on management behavior of supervisor on subordinates. Judging from the literal, researchers use "supervision" but not "management". This illustrates abusive supervision theory emphasizes the management behavior of supervisor.

Abusive supervision has four features:

1) The perception of subordinates on abusive supervision is one kind of subjective judgment.

2) Abusive supervision is continuous behavior, once or occasional abusive behavior cannot be called abusive supervision.

3) Abusive supervision concluding only verbal or nonverbal hostile acts not aggression of physical contact.

4) Abusive supervision refers to action, not intention, intention or motive cannot be called abusive supervision [12].

\section{B. Work-family Conflict}

WFC is included in the research area of work stress. The concept of WFC already reach basic consensus in academia. WFC is usually defined as the intraoral conflict caused by the incompatibility of role stress between work area and family area [15]. There are many similar concepts, for example, work family interaction, work family involvement, work family interface, work family enrichment, work family role conflict, work interference with family, family interference with work, and so on. That's because of the different emphasis of research. All these concepts are parts of the research contents of WFC. There are mainly two kinds of understanding of the structure of WFC according to direction and form. In the perspective of direction, there are two kinds of structure of WFC which are work to family conflict and family to work 
conflict [17]. In the perspective of form, there are three dimensions of WFC, which are time-based WFC, strain-based WFC, and behavior-based WFC [15].

\section{Direct Impact Mechanism of Abusive Supervision on Work-family Conflict}

The theory of the impact of supervisor on subordinates' stress is the research foundation of the research on impact mechanism of abusive supervision on WFC. Many researchers already pointed out that supervisor can affect subordinates' stressor, and then lead to work stress [18]. As one kind of work stress, the impact mechanism of supervisor on WFC attracts much attention of scholars. Researches mainly focus on social support theory proposing supervisor support can buffer conflict between work and family from positive perspective [2][19]. However, there are few researches on the negative effect of supervisor. Tepper (2000) [12] proposed that abusive supervision can enhance employees' WFC from negative perspective bring us new research angle, but this only in early stage. Carlson et al. (2011) [20] affirmed abusive supervision can positively affect WFC through empirical study. On mechanism, Tepper (2000) [12] proposed that the injustice caused by abusive supervision can lead to excessive attention of employee on work. As a result, they didn't have enough time accompany their family. Then this causes workfamily conflict. Restubog et al. (2011) [9] thought abusive supervision can cause psychological distress which increases the aggression of family life, aggravates work-family conflict. Though the mechanism between abusive supervision and WFC still under debate, abusive supervision can increase employee's work-family conflict is already reach basic consensus in academia. Consequently, we hold the opinion that abusive supervision can positively affect work-family conflict.

\section{The Mediation Model of Abusive Supervision Impact on WFC}

The mediators of abusive supervision and WFC mainly focus on organizational justice and psychological distress. Tepper (2000) [12] proposed that the injustice caused by abusive supervision can lead to excessive attention of employee on work from organizational justice perspective. As a result, they didn't have enough time accompany their family. Then this causes work-family conflict. From psychological distress perspective, based on stress interaction theory, Restubog et al. (2011) [9] thought abusive supervision can cause psychological distress of employee, for example, fear and anxiety. They will transfer the abuse to family through family nuisance behavior, for example, criticism ignored and insult family. This is another form of work-family conflict. Carlson et al. (2011) [20] also pointed out that abusive supervision can cause many dysfunctional individual consequence like depression [21], lower self-efficacy and higher somatic complaints [22], lower life satisfaction [12], these are all performance of psychological distress. The consequence of individual transfer the stress the perceived in work to family is the upgrade of work-family conflict [23].

We think organizational justice and psychological distress are not two separate variables, they have interaction effect. Organizational justice affects psychological distress, and they both mediate the relationship between abusive supervision and work-family conflict (refer with: Fig. 1).

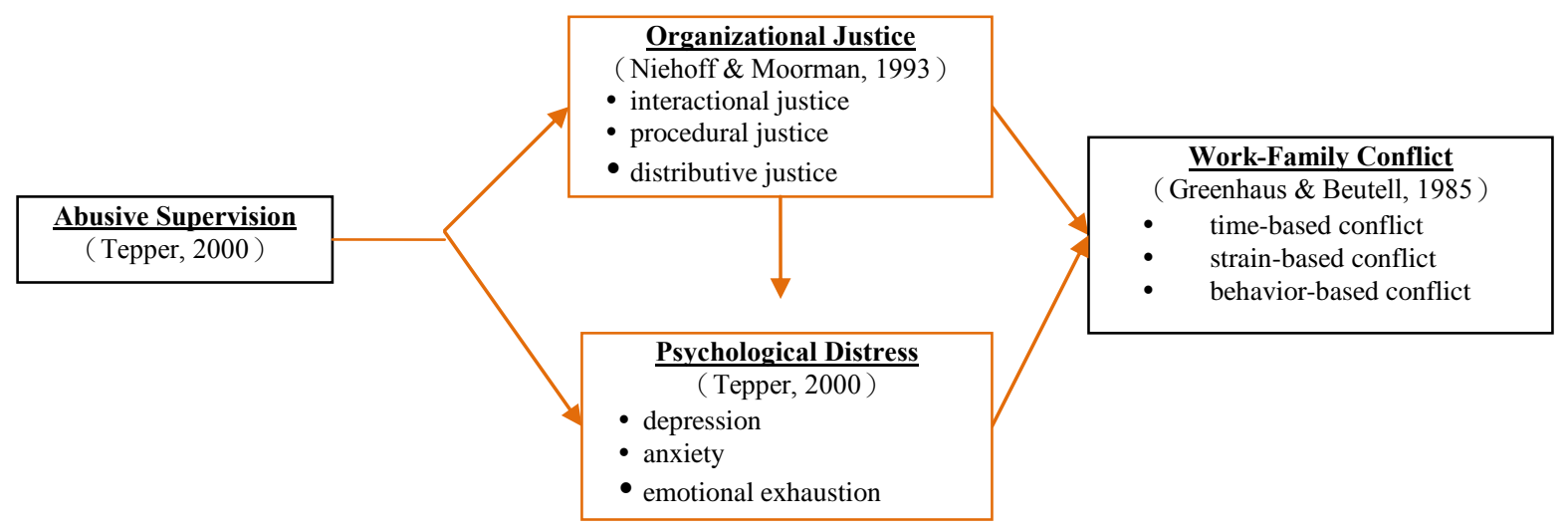

Fig. 1 Impact model of Abusive Supervision on Work-Family Conflict: A Mediation effect of Organizational Justice and Psychological Distress

There are mainly three paths of abusive supervision impact on work-family conflict. Abusive supervision affect work-family conflict by organizational justice is the first path. Abusive supervision of the supervisor can affect employee's perception of organizational justice, and then they need more time understanding and adapting this thought. As a result, the time they leave for their family will decrease, which cause time-based work-family conflict.
This organizational justice includes interactional justice, procedural justice, and distributive justice. The second path is abusive supervision affect work-family conflict by psychological distress. Abusive supervision of the supervisor can lead to employee's psychological distress. The experience of abuse haunts from beginning to the end, cause problems like depression, anxiety, and emotional exhaustion. Consequently, subordinate brings the negative emotion back home through "kicked the dog effect" and "emotional contagion", affects the 
atmosphere of a family, and causes work-family conflict. The third path is abusive supervision affects employee's perception of organizational justice, this perception leads to psychological distress, then affect work-family conflict. Abusive supervision of the supervisor can affect employee's perception of organizational justice, this perception leads to psychological distress, and then the time they leave for their family will decrease, and they brings the negative emotion back home, which finally causes work-family conflict.

\section{Conclusion and Summary}

The mediation mechanism of abusive supervision and work-family conflict still has the debate on organizational justice and psychological distress. But the authors hold the point that integrating organizational justice and psychological distress as mediation mechanism is a new angle. Organizational justice can negative affect psychological distress. Adams \& Freedman (1976) [23] pointed out that the perception of injustice can affect self-esteem. Tepper (2000) [12] thought the perception of injustice of individual on organization can cause psychological distress. And Tepper (2000) [12] also thought organizational justice can be the mediator between abusive supervision and psychological distress. Consequently, this thesis brings the negative relation of organizational justice and psychological distress to the mediator mechanism between abusive supervision and workfamily conflict, proposes integrated mediator mechanism model.

\section{Acknowledgment}

This research was funded by the National Natural Science Foundation of China (71172119, 71302139, 71102092), the Young People Project of Humanities and Social Science Foundation of Chinese Ministry of Education (14YJC630054), the Statistical Scientific Research Foundation of the National Statistics of China (2014LZ52), the Fundamental Research Foundation for Universities of China (22614816) and the Young People Project of Scientific Research Foundation of Dongbei University of Finance and Economics (DUFE2014Q46).

\section{References}

[1] S. Parasuraman, J.H. Greenhaus and C.S. Granrose, Role stressors, social support, and well-being among two-career couples, Journal of Organizational Behavior, vol.13, pp.339-356, 1992.

[2] D.S. Carlson and P.L.Perrewé, The role of social support in the stressor-strain relationship: an examination of work-family conflict, Journal of Management, vol.25, pp.513-540, 1999.

[3] J.R. Edwards and N.P.Rothbard, Mechanisms linking work and family: clarifying the relationship between work and family constructs, Academy of Management Review, vol.25, pp.178-199, 2000.
[4] S. Aryee, E.S. Srinivas and H.H. Tan, Rhythms of life: antecedents and outcomes of work-family balance in employed parents, Journal of Applied Psychology, vol.90, pp.132-146, 2005.

[5] B.L. Taylor, R.G. DelCampo and D.M. Blancero, Work-family conflict/facilitation and the role of workplace supports for u.s. hispanic professionals, Journal of Organizational Behavior, vol.30, pp.643-664, 2009.

[6] J.D. Goodstein, Institutional pressures and strategic responsiveness: employer involvement in work-family issues, Academy of Management Journal, vol.37, pp.350-382, 1994.

[7] J.E. Jennings and M.S. McDougald, Work-family interface experiences and coping strategies: implications for entrepreneurship research and practice, Academy of Management Review, vol.32, pp.747-760, 2007.

[8] E.E. Kossek and C. Ozeki, Work-family conflict, policies, and the joblife satisfaction relationship: a review and directions for organizational behavior-human resources research, Journal of Applied Psychology, vol.83, pp.139-149, 1998.

[9] S.L.D. Restubog, K.L.Scott, and T.J.Zagenczyk, When distress hits home: the role of contextual factors and psychological distress in predicting employees' responses to abusive supervision, Journal of Applied Psychology, vol.96, pp.713-729, 2011.

[10] J.M. Hoobler and D.J.Brass, Abusive supervision and family undermining as displaced aggression, Journal of Applied Psychology, vol.91, pp.1125-1133, 2006.

[11] D.S. Carlson, M.Ferguson, P.L.PerrewÉ, and D.Whitten, The fallout from abusive supervision: an examination of subordinates and their partners, Personnel Psychology, vol.64, pp.937-961, 2011.

[12] B.J. Tepper, Consequences of abusive supervision, Academy of Management Journal, vol.43, pp.178-190, 2000.

[13] M.S. Mitchell and M.L.Ambrose, Abusive supervision and workplace deviance and the moderating effects of negative reciprocity beliefs, Journal of Applied Psychology, vol.92, pp.1159-1168, 2007.

[14] Y.L. Zhu, J.Y. Duan, B. Ling, Concept definition, influence factor, and consequence of abusive supervision, Foreign Economics \& Management, vol.12, pp.25-32, 2009.

[15] J.H. Greenhaus and N.J. Beutell, Sources of conflict between work and family roles, Academy of Management Review, vol.10, pp.76-88, 1985.

[16] L. Zhang, D. Zhang, Work-family conflict research: international present and future, Nankai Business Review, vol.9, pp.55-63, 2006.

[17] M.R. Frone, M. Russell and M.L. Cooper, Antecedents and outcomes of work-family conflict: testing a model of the work-family interface, Journal of Applied Psychology, vol.77, pp.65-78, 1992.

[18] T.W. Britt, J.Davison, P.D.Bliese, and C.A.Castro, How leaders can influence the impact that stressors have on soldiers, Military Medicine, vol.169, pp.541-545, 2004.

[19] L.T. Thomas and D.C.Ganster, Impact of family-supportive work variables on work-family conflict and strain: a control perspective, Journal of Applied Psychology, vol.80, pp.6-15, 1995.

[20] B.J. Tepper, Abusive supervision in work organizations: review, synthesis, and research agenda, Journal of Management, vol.33, pp.261-289, 2007.

[21] M.K. Duffy, D.C.Ganster, and M.Pagon, Social undermining in the workplace, Academy of Management Journal, vol.45, pp.331-351, 2002.

[22] M. Westman, Stress and strain crossover, Human Relations, vol.54, pp.717-751, 2001.

[23] J.S. Adams and S. Freedman, Equity theory revisited: comments and an annotated bibliography, In L. Berkowitz and E. Walster (Eds. ), Equity Theory: Toward a General Theory of Social Interaction, New York: Academic Press, 1976, pp. 43-90. 